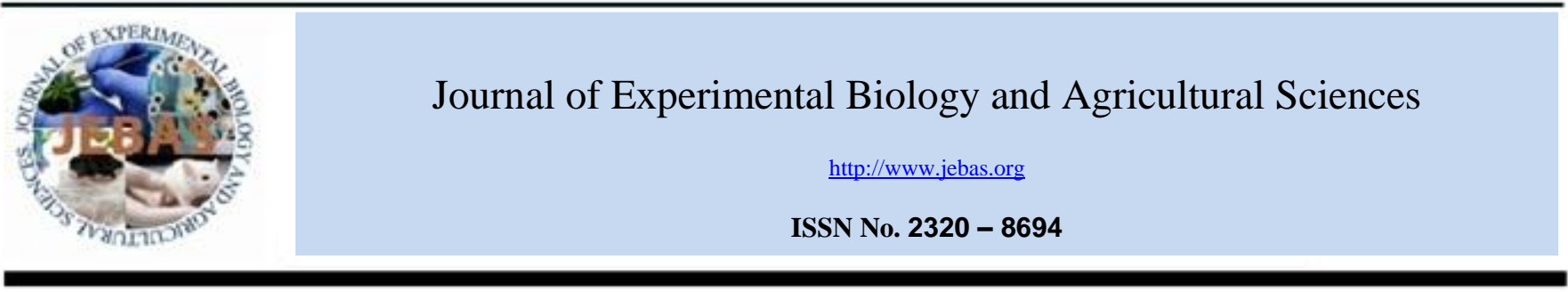

\title{
PHYSIO-BIOCHEMICAL AND MOLECULAR CHARACTERIZATION FOR DROUGHT TOLERANCE IN RICE GENOTYPES AT EARLY SEEDLING STAGE
}

\author{
Al-Ashkar IM ${ }^{1}$, Zaazaa EI ${ }^{1}$, EL Sabagh A ${ }^{2, *}$, Barutçular $C^{3}$ \\ ${ }^{1}$ Department of Agronomy, Faculty of Agriculture, University of Al-Azhar, Cairo, Egypt \\ ${ }^{2}$ Department of Agronomy, Faculty of Agriculture, University of Kafrelsheikh, Egypt \\ ${ }^{3}$ Department of Field Crops, Faculty of Agriculture, University of Cukurova, Turkey
}

Received - October 18, 2016; Revision - November 01, 2016; Accepted - November 06, 2016

Available Online - November 13, 2016

DOI: http://dx.doi.org/10.18006/2016.4(Issue6).675.687

KEYWORDS
Water stress
PEG
Antioxidant enzymes
Oryza sativa
Growth traits
Physiological aspects
SSR markers

\begin{abstract}
The aim of the current investigation was to study the influence of drought-stressed by using PEG on some rice genotypes at seedling stage. The performance was judged by growth, physiological, biochemical and molecular constituents at seedling stage. The results of study suggested that growth attributes were reduced under different drought stress (70 and $140 \mathrm{~g} / \mathrm{L} \mathrm{PEG)} \mathrm{in} \mathrm{most} \mathrm{of} \mathrm{the} \mathrm{cases} \mathrm{as}$ compared with control. Among various tested genotypes IRAT 259, Line 7 and Line 8 exhibited the lowest reduction values of relative water content, chlorophyll content and membrane stability index at 70 and 140 drought levels. The Line 8 produced the highest amount of proline under stress conditions which is indicating its highest tolerance to drought stress. The antioxidant enzymes such as catalase, peroxidase and polyphenol oxidase were induced by the drought levels. The growing expressions of antioxidant enzymes assist the plant for adaptation of plant under environmental conditions and tolerate stress. The IRAT 259 has highest increase percentage in antioxidant enzymes under stress. Total sixteen SSR primers examine for characterizing the power of each SSR primer by calculating polymorphic information contents and a total of 41 alleles were amplified using 16 SSR primers. The variation in number of amplified alleles per primer ranged from one allele as for wmc27 to five alleles for wmc179 and wmc 215, with an average of 2.56 alleles. The highest value was $100 \%$ polymorphism belonged to
\end{abstract}

* Corresponding author

E-mail: ayman.elsabagh@agr.kfs.edu.eg (EL Sabagh A)

Peer review under responsibility of Journal of Experimental Biology and Agricultural Sciences.

Production and Hosting by Horizon Publisher India [HPI] (http://www.horizonpublisherindia.in/).

All rights reserved.
All the article published by Journal of Experimental Biology and Agricultural Sciences is licensed under a Creative Commons Attribution-NonCommercial 4.0 International License Based on a work at www.jebas.org.

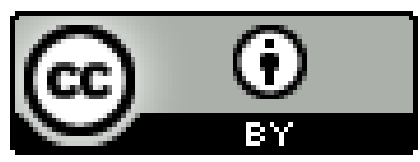


13 out of the 16 primers. Phylogenetic analyses per primer were ranged from 0.00 to 0.794 with an average of 0.427 . Average observed heterozygosity ranged from 0.00 to 0.670 with an average of 0.45 . It was found the value of heterozygosity was 0.00 to 0.670 and the mean value of heterozygosity was 0.45 . On the basis of phenotypic and genetypic (reaction with markers) performances under drought stress conditions, the Line 8 and the Line 7 can be recommended as a drought tolerant and a drought sensitive, respectively. This result can be acclaimed the important source for genetic diversity of rice in future breeding programs.

\section{Introduction}

Rice (Oryza sativa L.) is considered the most essential food crops and it needs huge amount of water as compare to other crops during growth life cycle (Wang et al., 2012). Rice plays a major role as a staple food which providing nutrition to more than three billion people and comprising $50-80 \%$ of their daily calorie intake (Khush, 2005). Rice crop plays an important role in Egypt for strengthen self-sufficiency of food and for maximizing the export of rice as strategic crop. Furthermore, the average yield of rice has to be increased by $25-30 \%$ to face the demands of the increase of population growth rate (RRTC, 2013). Identifying rice genotypes and breeding lines with high levels of tolerance to drought to use as donors in breeding and gene discovery is one of the most challenges for rice research (Serraj \& Atlin, 2008).

Drought is one of the most important environmental stresses that influence the growth and development of plants and it is also an important challenge to agricultural researchers and plant breeders. Water stress causes severe threat in production of rice and it affects morphological, physiological, biochemical and molecular characteristics of rice crops along with its productivity. Hence, with decline worldwide water availability for agriculture there is a need for improving drought adaptation in rice and screening of drought tolerance genotypes becoming necessary. Drought tolerance is complex phenomenon which depends on the combined function of different morphological, physiological, biochemical and molecular properties. The mechanisms associated with the tolerance to water-stress and the systems that regulate adaptation of plant to water stress in rice have been completed studied (Pandey \& Shukla, 2015).

Drought stress influence the expressions of antioxidant in plants, osmotic modification, chlorophyll and transpiration reduction and inhibition of growth (Gupta \& Huang, 2014). The different stages of growth exhibited catalase and peroxidase activity and with the growing drought intensity accumulation of proline also increases with high levels of stress (Mahdi et al., 2007). Biotic and abiotic stresses conditions also have negative impact on cell due to accumulation reactive oxygen species (Vaidyanathan et al., 2003).

According to Pandey \& Shukla (2015) development and selection of drought tolerant rice varieties depend on the understanding of the different mechanisms that manage the productivity of rice under water stress condition. Molecular characterization of the available genotypes is beneficial for the evaluation of the genetic potential of the rice crops and help in stop erosion which can justified here as a reduction of genetic diversity in time (Manifesto et al., 2001). Therefore, the objectives of the present study were: (1) to evaluate and screen the available rice genotypes for the drought tolerance and to develop comprehensive understanding of the mechanism of plants response against drought stress with the help of integrated approach of combining mechanisms based on growth, morphological, physiological and biochemical related to drought tolerance and (2) estimate genetic diversity of six rice genotypes using molecular markers technique.

\section{Materials and Methods}

The present investigation was carried out at the Cell and Tissue Culture Laboratory of the Agronomy Department, Faculty of Agriculture, Al-Azhar University, Nasr City, Cairo, Egypt. Six rice genotypes including the three varieties viz., IRAT 170 (check), IRAT 259 (drought-tolerant) and Giza 182 (droughtsensitive) as well as the lines (Line 7, Line 8 and Line 9) were tested for drought tolerance. Mature rice seeds, were husked manually, and washed for 2-5 min with sterile distilled water. Seeds were then cultured on; a modified MS medium (Murashige \& Skoog, 1962) supplemented with various levels of polyethylene glycol 6000 ( 0,70 and $140 \mathrm{~g} / \mathrm{L}$ PEG). The basal medium was supplemented with $30 \mathrm{~g} / \mathrm{L}$ sucrose and 6 $\mathrm{g} / \mathrm{L}$ agar. The cultures were incubated at $28 \pm 2{ }^{\circ} \mathrm{C}$ with $16 \mathrm{~h}$ photoperiod for 20 days. All the treatments were laid in a complete randomized design and replicated five times and the replicate was included 10 seeds. An analysis of variance was predestined for all traits according to Steel et al. (1996) to define the significant differences between genotypes.

\subsection{Growth, physiological and biochemical traits measured}

The performance of rice genotypes was studied under drought stress conditions at the early seedling stage; Root and shoot lengths $(\mathrm{cm})$ and fresh and dry weights $(\mathrm{g})$ were measured. Relative water content was measured by the method described by Schonfeld et al. (1988) with some modification. Proline was measured according to Bates et al. (1973). Chlorophyll content (SPAD unit), was measured on three leaf seedlings taken from each replicate by chlorophyll meter (SPAD-502, Soil- Plant Analysis Department (SPAD) section, Minolta camera Co., Osaka, Japan) by Minolta (1989). 
Membrane stability index (\%) is a measure phenomenon of drought resistance and the level of MSI was calculated by modifying Sairam et al. (2002), leaves of control and droughtstressed plants were collected and thoroughly washed with distilled water. $100 \mathrm{mg}$ of leaf sample was placed in $10 \mathrm{ml}$ of double distilled water at $40^{\circ} \mathrm{C}$ for $30 \mathrm{~min}$ and thereafter, electric conductivity $(\mathrm{C} 1)$ was measured with conductivity meter. It was followed by calculation the electric conductivity (C2) the same samples were settled on boiling water bath (100 $\left.{ }^{\circ} \mathrm{C}\right)$ for $15 \mathrm{~min}$. The MSI was calculated using following formula:

$\mathrm{MSI}=[1-(\mathrm{C} 1 / \mathrm{C} 2)] \times 100$

For antioxidant enzymes analysis, fresh leaf leaves samples $(0.2 \mathrm{~g})$ were ground in liquid nitrogen and homogenized in an ice-bath in $4 \mathrm{ml}$ homogenizing solution containing $50 \mathrm{mM}$ potassium phosphate buffer and $1 \%$ (w/v polyvinylpyrrolidone) $(\mathrm{pH}$ 7.8). The homogenate was centrifuged at $14000 \mathrm{rpm}$ at $4^{\circ} \mathrm{C}$ for $10 \mathrm{~min}$ and the resulting supernatant was used as enzyme source for catalase, peroxidase and polyphenol oxidase assays.

Assay of catalase, the assay mixture in total volume of $3 \mathrm{~mL}$ contained $1.5 \mathrm{~mL}$ of $100 \mathrm{mM}$ phosphate buffer ( $\mathrm{pH}$ 7.2), 0.5 $\mathrm{mL}$ of $(\mathrm{v} / \mathrm{v}) \mathrm{H}_{2} \mathrm{O}_{2}$ and $0.03 \mathrm{ml}$ of enzyme. The final volume was made $3 \mathrm{ml}$ by adding distilled water. The reaction was started by adding enzyme and change in optical density was measured at $240 \mathrm{~nm}$ at $60 \mathrm{~s}$. The enzyme activity was showed by calculating the magnitude of decomposed $\mathrm{H}_{2} \mathrm{O}_{2}$ according to Aebi (1984).

For assay of peroxidase (POD), determined by spectrophotometer at $420 \mathrm{~nm}$, according to Chance \& Maehly (1955) and Assay of polyphenol oxidase (PPO), determined according to Duckworth \& Coleman (1970) through spectrophotometrically at wave length $420 \mathrm{~nm}$ at $25^{\circ} \mathrm{C}$.

\subsection{Molecular characterization}

\subsubsection{DNA extraction and PCR amplification}

A $500 \mathrm{mg}$ sample of frozen young leaves of the six rice genotypes were ground to powder in a mortar and a pestle in the presence of liquid nitrogen. The DNA extraction was done using the cetyltrimethyl ammonium bromide (CTAB) method (Saghai-Maroof et al., 1984). Twenty SSR primers were used in the present investigation. The PCR products were electrophoreses in $2 \%$ agarose gels stained with ethidium bromide and visualized under UV light or were separated via capillary electrophoresis using a QI Axcel Advanced system device.

\subsubsection{Data handling of SSR marker}

SSR data was registered based on the existence of the amplified Products for each primer To investigate the discriminatory power of each SSR primer, the polymorphic information content (PIC) was measured according to Smith et al. (2000). As well as, Heterozygosity (Ho) was measured according to (Hormaza, 2002).

\section{Results and Discussion}

\subsection{In vitro screening of rice genotypes for drought tolerance}

As screening technique, the survival ability of the six rice genotypes was evaluated by culturing mature seeds on MS medium supplemented by three doses of PEG-6000 $(0,70$ and $140 \mathrm{~g} / \mathrm{L}$ )during germination stage. Highly significant differences were recorded among two-way interaction (genotypes and drought levels) $(\mathrm{P} \leq 0.01)$ for all studied traits, revealing the presence of genetic diversity in the material used (Figure 1 and 2).

\subsection{Growth traits as affected by drought stress}

In all genotypes, the seedlings growth decreased with increasing the levels of stress (Figure 1). Among various tested genotypes, lowest reduction of shoot length $(0.00 \%)$ was observed in IRAT 259 while the highest reduction (36.62\%) was reported from the genotype Giza 182 at $70 \mathrm{~g} / \mathrm{L}$ PEG induced stress. On the other hand, the reduction percentages were 19.44 and 67.83 for IRAT 259 and Line7 genotypes under $140 \mathrm{~g} / \mathrm{L}$ PEG stress treatments respectively. In the present study, IRAT 259 was followed by the Line 9 genotypes and registered as the lowest means reduction than other genotypes under level $70 \mathrm{~g} / \mathrm{L}$ PEG this thing is indicating that these genotypes are more tolerant and relatively showing small decreases in shoot length under drought stress (Figure 1). The present findings are in line with Lum et al. (2014) and in agreement with these findings, a previous study (EL Sabagh et al., 2015a).

Concerning shoot fresh weight, reduction percentages of all genotypes ranged from 23.38 to $41.67 \%$ (average $29.58 \%$ ) and 43.18 to $75.86 \%$ (average $57.14 \%$ ) under 70 and $140 \mathrm{~g} / \mathrm{L}$ PEG drought stress, respectively (Figure 1). Shoot fresh weight of the genotypes Giza 182 and Line 7 were more adversely affected than other genotypes by the 70 and $140 \mathrm{~g} / \mathrm{L}$ PEG stress treatments, respectively. The reduction range of shoot dry weight was 5.42 to $43.99 \%$ at $70 \mathrm{~g} / \mathrm{L}$ drought stress while the maximum reduction of shoot dry weight $(63.77 \%)$ was recorded in genotype IRAT 170 and it was followed by IRAT $259(60.75 \%)$ at $140 \mathrm{~g} / \mathrm{L}$ PEG induced drought stress (Figure 1 ). The lowest reduction of mean shoot dry weight (less than $15 \%$ ) was recorded at the Line 8 genotype under $70 \mathrm{~g} / \mathrm{L}$ PEG followed Giza 182 and Line 9 genotypes.

Roots play great role in plant existence under stress conditions. It was observed that under stress conditions a significant reduction was reported in root length. The lowest reduction in root length (8.29 and $14.85 \%$ ) was recorded at the genotypes of Line 8 and IRAT 259 while the highest reduction (30.73 and $57.14 \%$ ) was observed at IRTAT 259 and Line 8 under 70 and $140 \mathrm{~g} / \mathrm{L}$ PEG induced stresses, respectively (Figure1). 


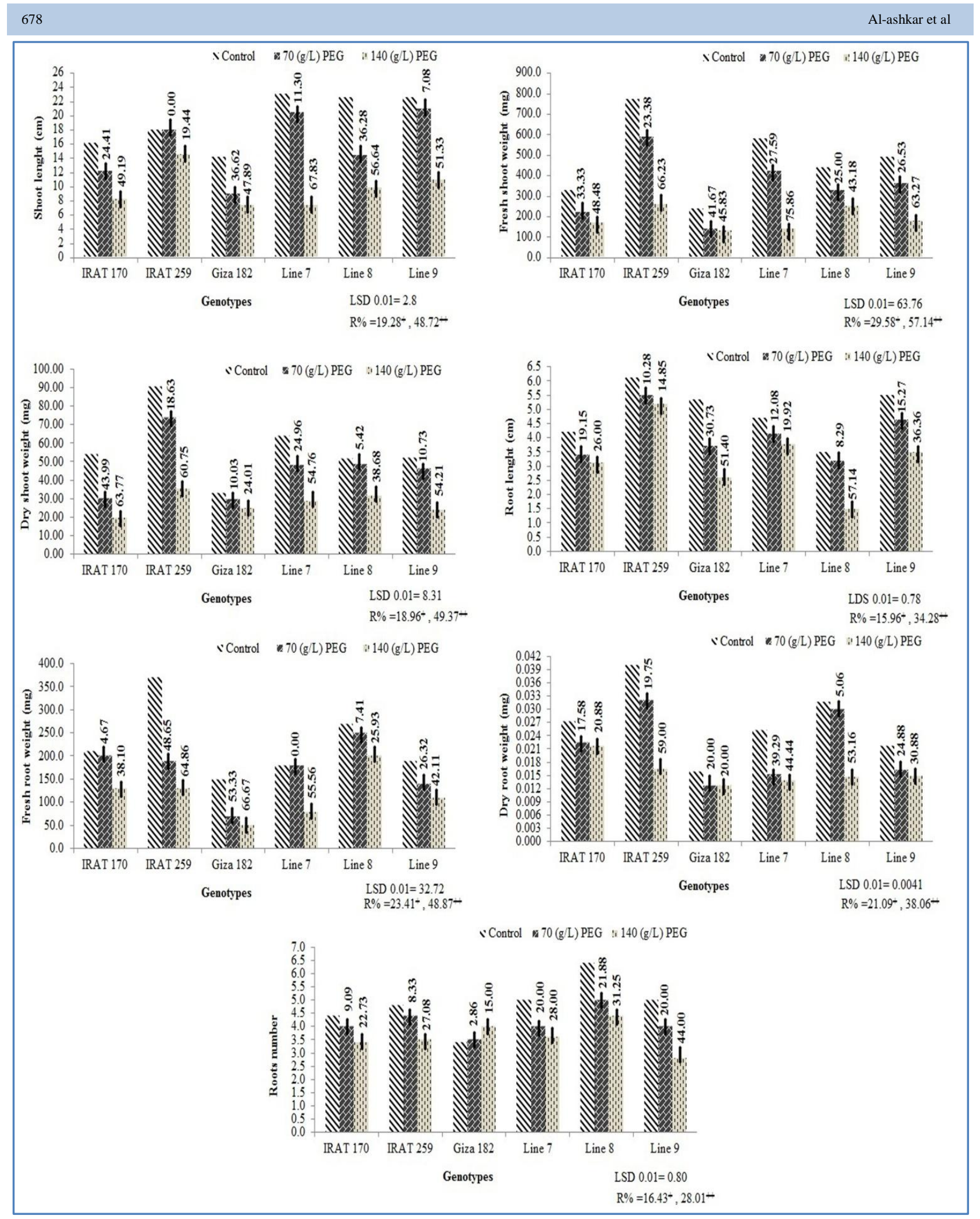

Figure 1 Mean of six rice genotypes of seven growth traits under $(0,70$ and $140 \mathrm{~g} / \mathrm{L})$ polyethylene glycol. NB: Numerical values above bars showed the percentage reduction in the trait relative to the control; $\mathrm{R} \%=$ reduction percentage; ${ }^{+,++}$Grand mean of reduction percentage at 70 and $140 \mathrm{~g} / \mathrm{L}$ PEG, respectively. 
Table 1 Size of DNA fragments generated from SSR analysis of six rice genotypes.

\begin{tabular}{|c|c|c|c|c|c|c|c|}
\hline \multirow[t]{2}{*}{ Markers } & \multirow{2}{*}{$\begin{array}{l}\text { Product size } \\
\text { (bp) }\end{array}$} & \multicolumn{6}{|c|}{ Genotypes } \\
\hline & & Giza 182 & IRAT 170 & IRAT 259 & Line 7 & Line 8 & Line 9 \\
\hline Xwmc27 & 400 & - & - & + & - & + & + \\
\hline \multirow[t]{2}{*}{ Xwmc147 } & 110 & - & + & - & - & - & - \\
\hline & 170 & - & - & + & - & + & + \\
\hline \multirow[t]{4}{*}{ Xwmc149 } & 190 & - & + & + & + & + & - \\
\hline & 205 & - & - & - & - & - & + \\
\hline & 240 & - & - & - & - & + & - \\
\hline & 270 & - & + & - & - & - & - \\
\hline \multirow[t]{3}{*}{ Xcfd1 } & 225 & + & - & + & + & + & + \\
\hline & 250 & - & - & + & - & + & - \\
\hline & 275 & - & - & - & - & + & - \\
\hline \multirow{5}{*}{ Xwmc179 } & 100 & - & + & - & - & + & - \\
\hline & 110 & + & - & + & + & - & - \\
\hline & 150 & - & + & - & - & - & + \\
\hline & 170 & - & - & + & - & + & - \\
\hline & 270 & - & - & + & - & + & + \\
\hline \multirow[t]{5}{*}{ Xwmc215 } & 100 & + & - & - & + & - & + \\
\hline & 120 & - & - & + & - & - & - \\
\hline & 170 & - & - & + & + & - & - \\
\hline & 240 & + & - & + & + & + & + \\
\hline & 290 & - & - & + & - & - & - \\
\hline \multirow[t]{2}{*}{ Xwmc233 } & 270 & - & - & + & - & + & + \\
\hline & 300 & - & - & - & - & + & - \\
\hline \multirow[t]{3}{*}{ Xgwm249 } & 70 & + & - & + & - & - & - \\
\hline & 90 & - & + & - & - & - & - \\
\hline & 150 & - & - & + & - & + & - \\
\hline Xwmc387 & 160 & - & - & - & - & + & - \\
\hline \multirow[t]{3}{*}{ Xwmc169 } & 145 & - & + & - & - & + & + \\
\hline & 155 & - & - & + & - & + & - \\
\hline & 170 & - & - & + & - & + & + \\
\hline Xwmc44 & 220 & + & + & + & - & + & - \\
\hline \multirow[t]{2}{*}{ Xwmc14 } & 90 & - & - & - & - & + & - \\
\hline & 250 & - & - & - & - & + & - \\
\hline \multirow[t]{2}{*}{ Xwmc18 } & 70 & + & + & + & + & + & + \\
\hline & 270 & - & - & - & - & + & + \\
\hline \multirow[t]{2}{*}{ Xwmc31 } & 60 & + & + & + & + & + & + \\
\hline & 150 & - & - & - & - & + & - \\
\hline \multirow[t]{2}{*}{ Xwmc327 } & 120 & - & - & - & - & + & + \\
\hline & 130 & - & - & - & - & + & - \\
\hline \multirow[t]{3}{*}{ Xwmc8 } & 70 & + & + & + & + & + & + \\
\hline & 110 & - & - & + & - & + & + \\
\hline & 140 & - & - & - & - & + & + \\
\hline
\end{tabular}

(+) means present, (-) means absent

The genotype IRAT 259 maintained lower mean reduction (10.28 and 14.85\%) under 70 and $140 \mathrm{~g} / \mathrm{L}$ PEG levels, respectively. As shown in (Figure 1), root fresh weight was reduced significantly by media moisture deficit. Reduction percentages of genotypes ranged from 0.00 to $53.33 \%$ and 25.93 to $66.67 \%$ was recorded under 70 and $140 \mathrm{~g} / \mathrm{L}$ PEG drought stress, respectively. Further, higher reduction in root fresh weight was reported, which averaged 23.41 and $48.87 \%$ relative to the control under 70 and $140 \mathrm{~g} / \mathrm{L}$ PEG stress levels, respectively. Three genotypes (IRAT170, Line 7 and Line 8) showed low means reduction (less than $15 \%$ ) under $70 \mathrm{~g} / \mathrm{L}$ PEG level, this thing is suggesting that these genotypes are less sensitive to drought stress as compared to the three other genotypes. Similar type of findings was reported by Fraser et al. (1990). 
Regarding root dry weight, the reduction mean values of genotypes ranged from 5.06 for Line 8 to $39.29 \%$ for Line 7, and 20.00 for Giza 182 to $59.00 \%$ for IRAT 259 under 70 and $140 \mathrm{~g} / \mathrm{L}$ PEG stress, respectively with an averages of 21.09 and $38.06 \%$ overall genotypes under treatments, respectively (Figure 1). The Line 8 registered the lowest means reduction than other genotypes under level $70 \mathrm{~g} / \mathrm{L}$ PEG which is indicating that this genotype is tolerant to drought. With respect to the number of root, all genotypes exhibited means reduction in number of root under both treatments relative to the control treatment with same genotypes, except the Giza 182 registered increased under 70 and $140 \mathrm{~g} / \mathrm{L}$ PEG levels, which gave 2.86 and $15.00 \%$, respectively (Figure 1). Two genotypes registered low means reduction (less than 15\%) under $70 \mathrm{~g} / \mathrm{L}$ PEG in number of root were IRAT 170 (9.09\%) and IRAT 259 (8.33), indicating that these genotypes are more tolerant under this level of drought stress, but most genotypes recorded moderate means reduction under water stress treatment (140 g/L PEG).

It is evident from the results that PEG treatments had inhibitory effect on all the growth attributes of rice accessions. The genotypes which sensitive to drought stress are exhibited more decline in biomass as compared to the resistant genotypes. Similar observations were reported by Jiang \& Lafitte (2007) and Lum et al. (2014). Based on the results, a variation in drought tolerance was reported among various genotypes during seedling growth stage. So, results of study suggested that most drought-tolerant variety is IRAT 259 while the highest drought sensitive variety is Giza 182 (Figure 1). The major rice genotypes showed a significant decrease in shoot length at the various drought levels as compared with control in major traits. These results were in compliance with those of Mohammadkhani \& Heidari (2008). A significant reduction in root length for all genotypes was reported higher at high levels of drought as compare to control (Figure 1). These results were in compliance with those of Fraser et al.(1990) and Ahmad et al. (2013).

3.3 Physiological and biochemical traits as influenced by drought stress

Effect of drought on certain physiological and biochemical traits related to crop productivity in rice included relative water content, chlorophyll content, proline content, membrane stability index and antioxidant enzymes activities measured for three stress levels of 0, 70 and $140 \mathrm{~g} / \mathrm{L}$ PEG (Figure 2). Result of study suggest that the relative water content, chlorophyll content and membrane stability index are depressed by drought stress, while the level of proline content and antioxidant enzymes activities (polyphenol oxidase,peroxidase and catalase) increased when plants subjected to drought stress. The differences among the genotypes in response to drought stress for final germination were highly significant (Figure 2).

A significant variation was found in terms of the relative water content (RWC) in the leaves of plants due to drought stress in major genotypes compared the control (Figure 2). The data were agreement with those obtained by Halder \& Burrage (2003). Among the genotypes IRAT 170, Giza 182 and Line 9 were maintained the highest means reduction of RWC, which gave $8.61,12.40$ and $9.81 \%$ under $70 \mathrm{~g} / \mathrm{L}$ PEG and 22.57, 19.22 and $17.38 \%$ under $140 \mathrm{~g} / \mathrm{L}$ PEG, respectively. These genotypes lost high amount of leaf water when subjected to drought, and consequently they are considered sensitive to drought stress compared to the genotypes IRAT 259, Line 7 and Line 8, illustrating that these genotypes retained more water in leaf tissue under same drought stress. The average reduction was as much as 6.63 and $14.32 \%$ at 70 and $140 \mathrm{~g} / \mathrm{L}$ PEG, demonstrating that the genotypes are tolerant, similar results was reported by earlier researchers Alizade (2002) and Islam et al. (2011).

In this study, chlorophyll synthesis in plant was reduced due to drought stress conditions. The reduction percentages of chlorophyll content were 4.84 and $10.58 \%$ under 70 and 140 g/L PEG drought stress of all genotypes, respectively (Figure 2).The result suggests that this trait is more tolerant to drought stress. Reduction percentages under $70 \mathrm{~g} / \mathrm{L}$ PEG treatment ranged from $0.09 \%$ for the Line 8 to $9.12 \%$ for the Line 9 and from $1.80 \%$ for the Line 8 to $13.24 \%$ for the IRAT 170 under $140 \mathrm{~g} / \mathrm{L}$ PEG, indicating that these genotypes are more tolerant to drought stress. Evain et al. (2004) suggested that the lowest values of stomatal conductance, photosynthesis and relative water content cloud be due to stress conditions. Similar types of results were reported by Seemann \& Sharkey (1986) and Barutçular et al. (2016).

Membrane stability index decreased with increasing moisture stress and there were significant differences among the genotypes (Figure 2). The mean reduction of this trait was 3.65 and $7.51 \%$ under 70 and $140 \mathrm{~g} / \mathrm{L}$ PEG treatments respectively; this thing is suggesting that this trait is more tolerant to drought stress. The reduction mean values of genotypes ranged from 1.96 for Line 8 to $6.44 \%$ for IRAT 170 and 3.38 for Line 7 to $14.64 \%$ for IRAT 170 under 70 and 140 g/L PEG stress, respectively. Hence, the approach of tolerance of these genotypes to drought stress were reflected by its higher value of membrane stability index. These results are correspond with Munns (2002); Al-Ashkar\& El-Kafafi (2014) and EL Sabagh et al.(2015b).

Proline was accumulated in leaf of rice plants subjected to water stress and the highest accumulation was recorded in the severe stress treatment (Figure 2). Average proline content increased 23.90 and $45.93 \%$ under drought stress treatments of 70 and $140 \mathrm{~g} / \mathrm{L}$ PEG, respectively (Figure 2). The genotype IRAT 259 accumulated the highest proline content of 44.08 and $69.21 \%$ while Line 8 recorded 37.15 and $74.72 \%$ under 70 and $140 \mathrm{~g} / \mathrm{L}$ PEG, respectively, these results are in agreements with Pireivatloum et al. (2010); Lum et al. (2014) and EL Sabagh et al. (2016). Besides, acts as an excellent osmolyte; proline plays three major roles during drought stress, i.e., as a metal chelator, an antioxidative defence molecule and a signaling molecule (Hayat et al., 2012). 


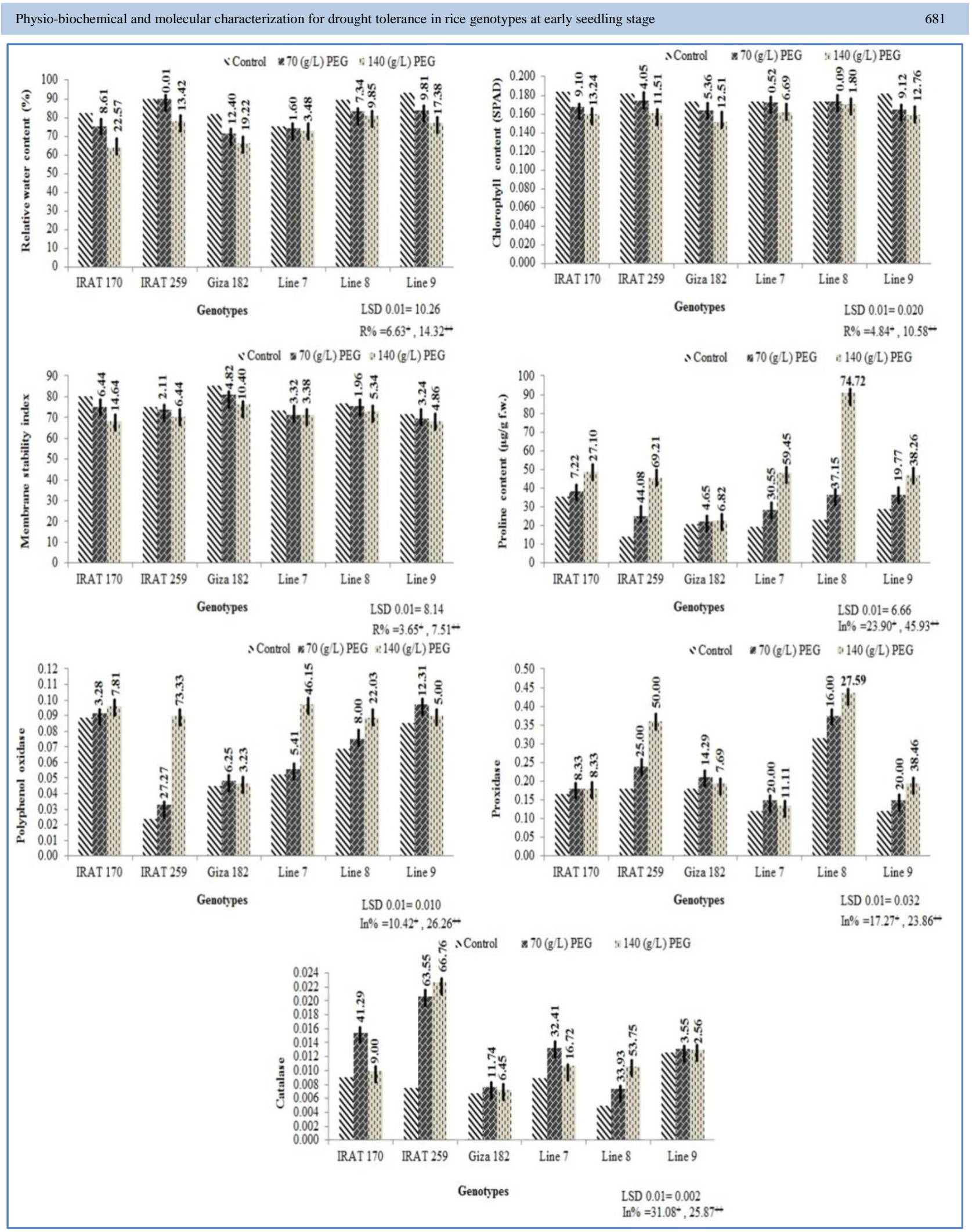

Figure 2 Mean of six rice genotypes of seven physiological and biochemical traits under ( 0,70 and $140 \mathrm{~g} / \mathrm{L})$ polyethylene glycol; NB: Numerical values above bars showed the percentage reduction or increase in the trait relative to the control; R\%= reduction percentage; In $\%=$ increase percentage, ${ }^{+,++}$Grand mean of percentage reduction or increase at 70 and $140 \mathrm{~g} / \mathrm{L}$ PEG, respectively. 
Proline accumulation might promote plant damage repair ability by increasing antioxidant activity during drought stress. In plants under water stress, proline content increases more than other amino acids, and this effect has been used as a biochemical marker to select varieties aiming to resist such conditions (Fahramand et al., 2014). Thus, proline content can be used as criterion for screening drought tolerant rice varieties.

The results of this study clearly showed that drought stress treatments of 70 and $140 \mathrm{~g} / \mathrm{L}$ PEG increased polyphenol content of 10.42 and $26.26 \%$, respectively (Figure 2). The genotypes IRAT 259 and Line 9 recorded highest increase percentage in phenol accumulation reached 27.27 and $12.31 \%$ under $70 \mathrm{~g} / \mathrm{L}$ PEG while the genotypes IRAT 259 and Line 7 recorded highest increase percentage in phenol accumulation under $140 \mathrm{~g} / \mathrm{L}$ PEG, which gave 73.33 and $46.15 \%$ respectively. High values of phenol indicated high stress tolerance, IRAT 259 and Line 9 genotypes showed more tolerance to drought stress than other genotypes. Agastian et al. (2000) observed that, polyphenol content was increased in various tissues of plants undera biotic stress conditions. A common effect of drought stress is the disturbance between the generation and quenching of reactive oxygen species (ROS) (Subhashini \& Reddy, 1990; Zheng \& Wang, 2001; Faize et al., 2011).

Peroxidase activity (POD) was significantly increased when plants of different genotypes were subjected to water stress. The average POD was 17.27 and $23.86 \%$ in all genotypes under 70 and $140 \mathrm{~g} / \mathrm{L}$ PEG, respectively (Figure 2). Catalase activity (CAT) also significantly increased under drought stress as compared with control for all the genotypes. Catalase activity increased 31.08 and $25.87 \%$ for all genotypes under drought stress treatments (70 and $140 \mathrm{~g} / \mathrm{L}$ PEG), respectively (Figure 2). The genotypes IRAT 259 recorded highest increase percentage in catalase activity $(63.55$ and $66.76 \%)$ under 70 and $140 \mathrm{~g} / \mathrm{L}$ PEG respectively, indicating its tolerance to drought stress. The genotype Giza 182 recorded the catalase activity (11.74 and 6.45\%) under 70 and $140 \mathrm{~g} / \mathrm{L}$ PEG respectively, indicating it's sensitive to drought stress. The plants are tolerance to drought-stress has higher levels of antioxidant systems and substrates (Athar et al., 2008).

In this research increased value of CAT and POD activities was reported in drought tolerant varieties, but, this value decreased in the sensitive varieties. These results are best way to protect the plants against $\mathrm{H}_{2} \mathrm{O}_{2}$. So, the growing of POD action could effectively withstand the oxidative stress that caused by stress (Mandhania et al., 2006). The tolerance genotypes against environmental stresses has been associated with higher activities of antioxidant enzymes and produced as protective defence system to counteract the oxidative injury that caused by drought stress in rice. The activities of antioxidants can effectively diminish the ROS, and cloud decrease passive effect of drought stress (Lum et al., 2014).

The results of reduction percentages for studied traits can be classified into three categories according to Farag (2005) these are (i) Drought tolerant traits included relative water content, chlorophyll content and membrane stability index reduced less than $15 \%$ under 70 and $140 \mathrm{~g} / \mathrm{L}$ PEG suggesting that these traits could be used as selection criteria for screening to drought resistant genotypes in rice; (ii) Moderately tolerant traits included growth traits, i.e. shoots and roots under $70 \mathrm{~g} / \mathrm{L}$ PEG reduced more than $15 \%$; and (iii) Drought susceptible traits like shoots and roots under $140 \mathrm{~g} / \mathrm{L}$ PEG reduced more than $30 \%$. It is worthy to note that the breeder should be taken into consideration to increase positive percentages in proline content and antioxidant enzymes activities (polyphenol oxidase, peroxidase and catalase) occurred under drought stress, which related to tolerance plant under these conditions (Farag, 2005).

3.4 Genetic diversity analysis based on SSR markers technique

\subsubsection{SSR analysis}

Twenty SSR primers were screened for their ability to amplify the genomic DNA from six rice genotypes. The number of amplification bands per primer varied from 1.0 as for primer Xwmc 27 to 5.0 for primer Xwmc 215 depending on the primer and the DNA sample. Among these 41 amplified fragments, $8.38 \%$ were not polymorphic while $91.62 \%$ was polymorphic among the six rice genotypes (Table 2). The highest value was $100 \%$ polymorphism belonged to 13 out of the 16 primers. An example of polymorphism with wmc147, wmc149, wmc179 and wmc215 are shown in Figure 3.The highest levels of polymorphism were recorded for wmc179 and wmc215 while the lowest levels of polymorphism were recorded for wmc27, wmc387, wmc18 and wmc31 (Table 1).

Using potential markers generated in the present research to improve drought tolerance-associated DNA markers are showed in Table 1. Specific DNA bands generated from analysis SSR primers here some rice genotypes reported to be drought tolerant/sensitive (on the basis of data performance/pedigree) were used. The results from Figure 3 and Table 1 revealed that DNA band at 120, 170 and $290 \mathrm{bp}$ are present in IRAT259 as drought tolerant, but not in Giza 182 as drought sensitive, when primer wmc 215 is used. On the other hand, specific DNA bands at about $100 \mathrm{bp}$ is present in Giza 182 as drought sensitive but not in the IRAT259 and IRAT170 as drought tolerant, when primer Xwmc215 was used. Moreover, specific DNA bands, generated from SSR primers (Table 1), could be used to characterize between IRAT259 (drought tolerance) and Giza 182 (drought sensitive). 
Table 2 Levels of genetic information generated by sixteen SSR primers on six rice genotypes.

\begin{tabular}{|c|c|c|c|c|c|c|}
\hline Primer & Sequence of primer $\left(5^{\prime}-3^{\prime}\right)$ & $\begin{array}{c}\text { No. of } \\
\text { amplification } \\
\text { products }\end{array}$ & $\begin{array}{l}\text { No. of } \\
\text { polymorphic } \\
\text { products }\end{array}$ & $\begin{array}{c}\text { Polymorphism } \\
(\%)\end{array}$ & PIC & Ho \\
\hline Xwmc27 & $\begin{array}{l}\mathrm{F}=\text { AATAGAAACAGGTCACCATCCG } \\
\mathrm{R}=\text { AGAGCTGGAGTAGGGCCAAAG }\end{array}$ & 1 & 1 & 100 & 0.00 & 0.00 \\
\hline Xwmc147 & $\begin{array}{l}\mathrm{F}=\text { AGAACGAAAGAAGCGCGCTGAG } \\
\mathrm{R}=\text { ATGTGTTTCTTATCCTGCGGGC }\end{array}$ & 2 & 2 & 100 & 0.320 & 0.00 \\
\hline Xwmc149 & $\begin{array}{l}\mathrm{F}=\text { ACAGACTTGGTTGGTGCCGAGC } \\
\mathrm{R}=\text { ATGGGCGGGGGTGTAGAGTTTG }\end{array}$ & 4 & 4 & 100 & 0.390 & 0.33 \\
\hline Xcfd1 & $\begin{array}{l}\mathrm{F}=\text { ACCAAAGAACTTGCCTGGTG } \\
\mathrm{R}=\text { AAGCCTGACCTAGCCCAAAT }\end{array}$ & 3 & 3 & 100 & 0.532 & 0.33 \\
\hline Xwmc179 & $\begin{array}{l}\mathrm{F}=\text { CATGGTGGCCATGAGTGGAGGT } \\
\mathrm{R}=\text { CATGATCTTGCGTGTGCGTAGG }\end{array}$ & 5 & 5 & 100 & 0.794 & 0.67 \\
\hline Xwmc 215 & $\begin{array}{l}\mathrm{F}=\text { CATGCATGGTTGCAAGCAAAAG } \\
\mathrm{R}=\text { CATCCCGGTGCAACATCTGAAA }\end{array}$ & 5 & 5 & 100 & 0.720 & 0.50 \\
\hline Xwmc233 & $\begin{array}{l}\mathrm{F}=\text { GACGTCAAGAATCTTCGTCGGA } \\
\mathrm{R}=\text { ATCTGCTGAGCAGATCGTGGTT }\end{array}$ & 2 & 2 & 100 & 0.375 & 0.16 \\
\hline Xgwm249 & $\begin{array}{l}\mathrm{F}=\text { CAAATGGATCGAGAAAGGGA } \\
\mathrm{R}=\text { CTGCCATTTTTCTGGATCTACC }\end{array}$ & 3 & 3 & 100 & 0.640 & 0.16 \\
\hline Xwmc387 & $\begin{array}{l}\mathrm{F}=\mathrm{CATTTTGACACCCACACTCG} \\
\mathrm{R}=\mathrm{CTGGATCCCCTCTTCGCTAT}\end{array}$ & 1 & 1 & 100 & 0.00 & 0.00 \\
\hline Xwmc169 & $\begin{array}{l}\mathrm{F}=\text { TACCCGAATCTGGAAAATCAAT } \\
\mathrm{R}=\text { TGGAAGCTTGCTAACTTTGGAG }\end{array}$ & 3 & 3 & 100 & 0.658 & 0.50 \\
\hline Xwmc44 & $\begin{array}{l}\mathrm{F}=\text { GGTCTTCTGGGCTTTGATCCTG } \\
\mathrm{R}=\text { TGTTGCTAGGGACCCGTAGTGG }\end{array}$ & 1 & 1 & 100 & 0.00 & 0.00 \\
\hline Xwmc14 & $\begin{array}{l}\mathrm{F}=\text { ACCCGTCACCGGTTTATGGATG } \\
\mathrm{R}=\text { TCCACTTCAAGATGGAGGGCAG }\end{array}$ & 2 & 2 & 100 & 0.500 & 0.16 \\
\hline Xwmc18 & $\begin{array}{l}\mathrm{F}=\text { CTGGGGCTTGGATCACGTCATT } \\
\mathrm{R}=\text { AGCCATGGACATGGTGTCCTTC }\end{array}$ & 2 & 1 & 50 & 0.625 & 0.33 \\
\hline Xwmc31 & $\begin{array}{l}\mathrm{F}=\text { GTTCACACGGTGATGACTCCCA } \\
\mathrm{R}=\mathrm{CTGTTGCTTGCTCTGCACCCTT}\end{array}$ & 2 & 1 & 50 & 0.245 & 0.16 \\
\hline Xwmc327 & $\begin{array}{l}\mathrm{F}=\text { TGCGGTACAGGCAAGGCT } \\
\mathrm{R}=\mathrm{TAGAACGCCCTCGTCGGA}\end{array}$ & 2 & 2 & 100 & 0.445 & 0.16 \\
\hline Xwmc8 & $\begin{array}{l}\mathrm{F}=\text { CACGCGCACATCTCGCCAACTAA } \\
\mathrm{R}=\text { CGTGGTCTAGTCCGCGTTGGGTC }\end{array}$ & 3 & 2 & 66 & 0.595 & 0.50 \\
\hline Total & & 41 & 39 & & & \\
\hline Mean & & 2.56 & & 91.62 & 0.427 & 0.25 \\
\hline
\end{tabular}

PIC = Polymorphic information content; Ho = Observed heterozygosity.

There reducibility of these variety-specific markers was confirmed in SSR analyses for which DNA isolation, PCR amplification, and gel electrophoresis were carried out separately. The technique of molecular marker has provided and helping in identification and genetic characterization of QTLs with positive effects on stress tolerance during various plant stages (Foolad, 2005). Comparatively, however, a limited research has been conducted to identify genetic markers associated with drought tolerance in different plant species. In the current research, genotypes analyzed were mainly identified according to various traits under water stress conditions. In this regard, the molecular characterization was more efficient in the generation of an unbiased picture of diversity than an agronomic approach.
3. 4.2 Levels of genetic information generated by SSR primers

A total of 41 alleles were amplified of sixteen SSR among rice genotypes. The variation in number of amplified alleles per primer ranged from one allele as for wmc27 to five alleles for wmc179 and wmc215, with an average of 2.56 alleles (Table 2). The amplified alleles varied from 70 to $400 \mathrm{bp}$ in sizes (Table 2). Polymorphism information content (PIC) provides information on allele diversity and frequency among genotypes. PIC differed greatly for sixteen SSR markers studied in six rice genotypes used in this study. Overall, the mean value of the PIC was ( 0.000 to 0.794$)$ and the average was (0.427) (Table 2). The lowest value was recorded for three SSR viz. wmc27, wmc387 and wmc44. While the maximum PIC value was 0.794 for primer wmc179. 


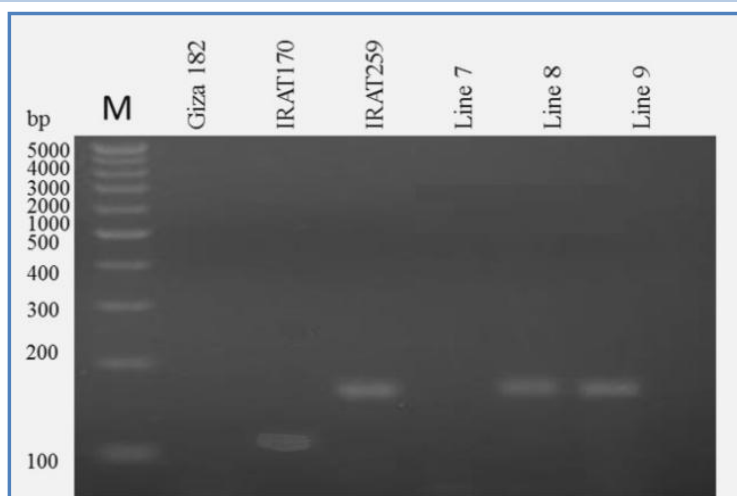

Wmc 147

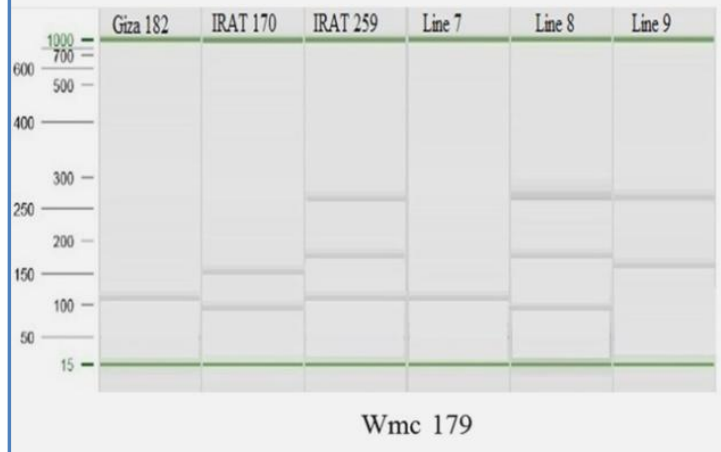

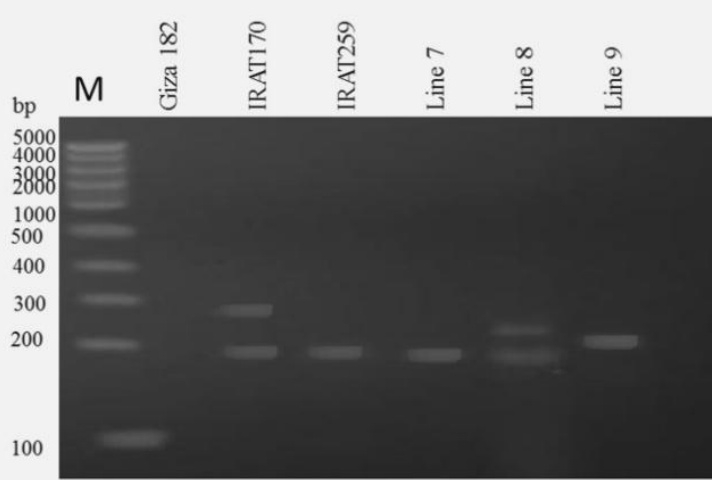

Wmc 149

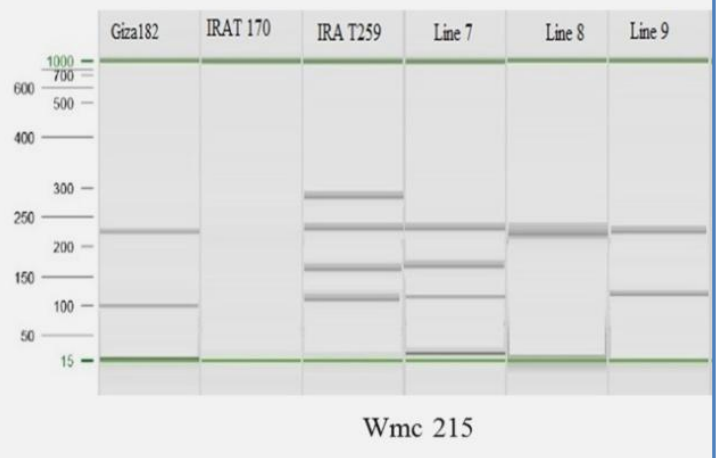

Figure 3 Examples of the SSR fingerprinting produced by Wmc147, Wmc149, Wmc179 and Wmc215 primers in the six rice genotypes.

It was observed, a significant and positive correlation (0.797) between PIC values and number of amplified alleles per primer. The value of heterozygosity were $(0.00$ to 0.67$)$ and the mean value of heterozygosity were $(0.25)$ (Table 2$)$. The lowest Ho value was recorded (0.00) for four SSR such as wmc147 primer, while the highest value recorded (0.67) for primers wmc179 (Table 2).

The results indicated that the total number of amplified alleles (41) as well as the average number of amplified alleles per primer (2.56) was relatively lower compared to previous results. These results agree with Babu et al. (2014) and Choudhary et al. (2013). These differences could be attributed to differences in genotypes as well as SSR primers. While, in this study, the mean value of (Ho) was higher (0.25) compared to the 0.01 recorded by Kyung et al. (2015) using 49 SSR primers. Only previously reported polymorphic SSR primers were employed in the present study. The low mean value of PIC (0.427) showed the presence of high genetic homogeneity among genotypes as well as additional polymorphic SSR primers to achieve successful characterization for entails improvement of rice genotypes. The mean value of PIC was (0.58) among 76 Korean rice varieties (Kyung et al., 2015)

\section{Conclusion}

Considering the results of this study, Significant differences were observed among rice genotypes in respect of all measurements (morphological, physiological and biochemical traits) and molecular analysis. Based on phenotypic and genetypic (reaction with markers) performances under drought stress conditions, the Line 8 and the Line 7 can be recommended as a drought tolerant and a drought sensitive, respectively. This result can be acclaimed the important source for genetic diversity of rice in future breeding programs.

\section{Acknowledgments}

We would like to express our sincere thanks and appreciation to Dr. E. I. Zaazaa, Agronomy Dept., Fac. of Agric., Al-Azhar Univ., Egypt, who provided us with rice genotypes. We also extend our thanks and appreciation to Prof. Abdullah AbduIaziz AL-Doss, Plant Production Department,College of Food and Agriculture Sciences, King Saud University, for allowing us to use biotechnology Laboratory.

\section{Conflict of interest}

Authors would hereby like to declare that there is no conflict of interests that could possibly arise. 


\section{References}

Aebi H (1984) Catalase in vitro.In: Packer L (Ed.) Methods in Enzymology. Oxygen Radicals in Biological systems, Academic Press, Orlando, FL., 105: 121-126.

Agastian P, Kingsley SJ, VireKanandan M (2000) Effect of salinity on photosynthesis and biochemical characteristics of mulberry genotypes. Photosynthetica 38: 287-290.

Ahmad M, Shahzad A, Iqbal M, Asif M, Hirani AH (2013) Morphological and molecular genetic variation in wheat for salinity tolerance at germination and early seedling stage. Australian Journal of Crop Science 7: 66-74.

Al-Ashkar IM, El-Kafafi SH (2014) Identification of traits contributing salt tolerance in some doubled haploid wheat lines at seedling stage. Middle East Journal of Applied Sciences 4: 1130-1140.

Alizade A (2002) Soil water and plants relationship 3rd Ed., Emam Reza University Press, Mashhad, Iran, 964-6582-21-4.

Athar H, Khan A, Ashraf M (2008) Exogenously applied ascorbic acid alleviates salt-induced oxidative stress in wheat. Environmental and Experimental Botany 63: 224-231.

Babu BK, Meena V, Agarwa V, Agrawal PK (2014) Population structure and genetic diversity analysis of Indian and exotic rice (Oryzasativa L.,) accessions using SSR markers. Molecular Biology Reports 41: 4329- 4339.

Barutçular C, Yıldııım M, Koç M, Akıncı C, Toptaş I, Albayrak O, Tanrıkulu A, EL Sabagh A (2016) Evaluation of SPAD chlorophyll in spring wheat genotypes under different environments. Fresenius Environmental Bulletin 25:12581266.

Bates LS, Waldren RP, Teare ID (1973) Rapid determination of free proline for water-stress studies. Plant and Soil 39: 205207.

Chance B, Maehly AC (1955) Methods in Enzymology II, Pp. 773-775.

Choudhary G, Ranjitkumar N, Surapaneni M, Deborah DA, Vipparla A, Anuradha G, Siddiq EA, Vemireddy LR (2013) Molecular genetic diversity of major Indian rice rultivars over decadal periods. PLoS One 8 : e66197.doi 10.1371/journal,pone,0066197.

Duckworth KW, Coleman JE (1970) Physicochernical and kinetic properties of mushroom tyrosinase. The Journal of Biological Chemistry 245 1613-1625.

EL Sabagh A, Omar A, Saneoka H,Barutçular C (2015a) Physiological performance of soybean germination and seedling growth under salinity stress.Dicle University Institute of Natural and Applied Science Journal 4 :6-15.

EL Sabagh A, Omar A, Saneoka H, Barutçular C (2015b) Comparative physiological study of soybean (Glycine max L.) cultivars under salt stress.YYU Journal of Agricultural Sciences $25: 269-248$.

EL Sabagh A, Sorour S, Morsi A, Islam MS, Ueda A, Barutcular C, Arioglu H, Saneoka H (2016) Role of Osmoprotectants and compost application in improving water stress tolerance in soybean (Glycine max L.). International Journal of Current Research 8:25949-25954.

Evain S, Flexas J, Moya I (2004) A new instrument for passive remote sensing: 2. Measurement of leaf and canopy reflectance changes at $531 \mathrm{~nm}$ and their relationship with photosynthesis and chlorophyll fluorescence. Remote Sensing of Environment 91: 175-185.

Fahramand M, Mahmoody M, Keykha A, Noori M, Rigi K (2014) Influence of abiotic stress on proline photosynthetic enzymes and growth. International Research Journal of Applied and Basic Sciences 8: 257- 265.

Faize M, Burgos L, Faize L, Piqueras A, Nicolas E, BarbaEspin G, Clemente-Moreno MJ, Alcobendas R, Artlip T, Hernandez JA (2011) Involvement of cytosolic ascorbate peroxidase and $\mathrm{Cu} / \mathrm{Zn}$ superoxide dismutase for improved tolerance against drought stress. Journal of Experimental Botany 62: 2599- 2612.

Farag HIA (2005) Diallel cross for estimating genetic parameters as basis of improving wheat (Triticumaestivum L,) under stress conditions, $\mathrm{Ph}, \mathrm{D}$, Thesis submitted to the Faculty of Agricultural sciences, Ain Shams University, Egypt.

Foolad M (2005) Breeding for abiotic stress tolerances in tomato. In: Ashraf M, Harris PJC (Eds), Abiotic Stresses Plant Resistance through Breeding and Molecular Approaches, The Haworth Press, Inc, New York USA pp, 613- 684.

Fraser T, Silk W, Rosr T (1990) Effect of low water potential on cortical cell length in growing region on maize roots. Plant Physiology 93: 648- 651.

Gupta B, Huang B (2014) Mechanism of salinity tolerance in plants physiological biochemical and molecular characterization. International Journal of Genomics 130: 21292141. http://dx.doi.org/10.1155/2014/701596.

Halder KP, Burrage SW (2003) Drought stress effects on water relations of rice grown in nutrient film technique. Pakistan Journal of Biological Sciences 6: 441- 446. DOI: 10.3923/pjbs.2003.441.444. 
Hayat S, Hayat Q, Alyemeni MN Wani AS, Pichtel J, Ahmad A (2012) Role of proline under changing environments, A review. Plant Signaling \& Behavor 7: 1456- 1466. DOI: $10.4161 / \mathrm{psb} .21949$

Hormaza JI (2002) Molecular characterization and similarity relationships among apricot (Prunus armeniaca L,) genotypes using simple sequence repeats. Theoretical and Applied Genetics 104: 321- 328.

Islam MS, Akhter MM, El Sabagh A, Liu LY, Nguyen NT, Ueda A, Yoshikuni M, Hirofumi S (2011) Comparative studies on growth and physiological responses to saline and alkaline stresses of Foxtail millet (Setaria italica L.) and Proso millet (Panicum miliaceum L.). Australian Journal of Crop Science 5: 1269-1277.

Jiang W, Lafitte R (2007) Ascertain the effect of PEG and exogenous $\mathrm{ABA}$ on rice growth at germination stage and their contribution to selecting drought tolerant genotypes. Asian Journal of Plant Sciences 6: 684- 687. DOI: 10.3923/ajps.2007.684.687.

Khush GS (2005) What it will take to feed 5.0 billion rice consumers in 2030. Plant Molecular Biology 59: 1-6. DOI: 10.1007/s11103-005-2159-5.

Kyung JL, Jong-Ro L, Gi-An L, Ho SL, Soon IK, Yong-Gu C, Yang-Hee C, Kyung-Ho M, Sok-Young L, Jong-Wook C (2015) Genetic diversity among Korean rice landraces (Oryzasativa L,) based on characters and SSR markers. Plant Breeding and Biotechnology 3: 216- 225. http://dx.doi.org/10.9787/PBB.2015.3.3.216.

Lum MS, Hanafi MM, Rafii YM, Akmar ASN (2014) effect of drought stress on growth proline and antioxidant enzyme activities of upland rice. The Journal of Animal and Plant Sciences 24: 1487-1497.

Mahdi DZ, Hemantaranjan A, Panday SK (2007) Antioxidative response of mung bean (Vigna radiate $\mathrm{L}$,) to salt stress. Legume Research 30: 57- 60.

Mandhania S, Madan S, Sawhney V (2006) Antioxidant defense mechanism under salt stress in wheat seedlings. BiologiaPlantarum 50: 227- 231.

Manifesto MM, Schlatter A, Hopp HE, Suarez EY, Dubcovsky J (2001) Quantitative evaluation of genetic diversity in wheat germplasm using molecular markers. Crop Science 41: 682690 .

Minolta Camera Co. (1989) Manual for chlorophyll meter SPAD-502. Minolta Camera Co, Osaka Japan.

Mohammadkhani N, Heidari R (2008) Drought induced accumulation of soluble sugars and proline in two maize varieties. World Applied Sciences Journal 3: 448- 452.
Munns R (2002) Comparative physiology of salt and water stress.Plant, Cell \& Environment 25: 239- 250.

Murashige T, Skoog F (1962) A revised medium for rapid growth and bioassays with tobacco tissue cultures. Physiologia plantarum 15: 473- 497.

Pandey V, Shukla A (2015) Acclimation and tolerance strategies of rice under drought stress. Rice Science 22: 147161. http://dx.doi.org/10.1016/j.rsci.2015.04.001.

Pireivatloum J, Qasimov N, Maralian H (2010) Effect of soil water stress on yield and proline content of four wheat lines. African Journal of Biotechnology 9: 36- 40.

RRTC (2013) National Rice Research Program: Final results of 2012 growing season. Sakha, Egypt.

Saghai-Maroof MA, Soliman KM, Jorgensen RA, Allard RW (1984) Ribosomal DNA spacer-length polymorphism in barley Mendelian inheritance chromosomal location and population dynamics. Proceedings of National Academy of Science USA 81: 8014- 8019.

Sairam RK, Rao KV, Srivastava GC (2002) Differential response of wheat genotypes to long term salinity stress in relation to oxidative stress antioxidant activity and osmolyte concentration. Plant Science 163: 1037- 1046. http://dx.doi.org/10.1016/S0168-9452(02)00278-9.

Schonfeld MA, Johnson RC, Carver BF, Mornhinweg DW (1988) Water relations in winter wheat as drought resistance indicators. Crop Science 28: 526- 531.

Seemann JR, Sharkey TD (1986) Salinity and nitrogen effects on photosynthesis ribulose-15-bisphosphate carboxylase and metabolite pool in Phaseolus vulgaris L. Plant Physiology 82: 555-560.

Serraj R, Atlin G (2008) Drought-resistant rice for increased rainfed production and poverty alleviation: a concept note. $\mathrm{p}$ 385-400. In: Serraj R, Bennett J, Hardy B (Eds.) Drought Frontiers in Rice: Crop Improvement for Increased Rain fed Production. International Rice Research Institute, Los Baños, Philippines.

Smith JSC, Kresovich S, Hopkins MS, Mitchell SE, Dean RE Woodman WL, Lee M, Porter M (2000) Genetic diversity among elite sorghum inbred lines assessed with simple sequence repeats. Crop Science 40: 226-232. doi:10.2135/cropsci2000.401226x.

Steel RGD, Torrie JH, Dickey DA (1996) Principles and procedures of statistics A biometrical approach 3rd ed McGraw Hill Book Company Inc. New York, USA: 334-381.

Subhashini K, Reddy GM (1990) Effect of salt stress on enzyme activities in callus culture to tolerant and susceptible 
rice cultures. Indian Journal of Experimental Biology 28: $277-$ 279.

Vaidyanathan H, Sivakumar P, Chakrabarsty R, Thomas G (2003) Scavenging of reactive oxygen species in $\mathrm{NaCl}$ stressed rice (Oryzasativa L,) differential response in salt-tolerant and sensitive varieties. Plant Science 165:1411-1418. DOI: 10.1016/j.plantsci.2003.08.005.
Wang JH, Geng LH, Zhang CM (2012) Research on the weak signal detecting technique for crop water stress based on wavelet denoising. Advanced Materials Research 424: 966970. DOI:10.4028/www.scientific.net/AMR.424-425.966.

Zheng W, Wang SY (2001) Antioxidant activity and phenolic compounds in selected herbs. Journal of Agricultural and Food chemistry 49: 5165- 5170. 